\title{
Soybean and Maize Zoning in West African Economic and Monetary Union-A simulation Approach
}

\author{
Marcela dos Santos Müller ${ }^{1}$, Durval Dourado Neto ${ }^{1}$, Klaus Reichardt ${ }^{2}$, Luís Carlos Timm³, \\ Felipe Fadel Sartori ${ }^{1}$, Guilherme Felisberto ${ }^{1} \&$ Thaise Dieminger Engroff ${ }^{1}$ \\ ${ }^{1}$ Crop Science Department, Esalq, University of Sao Paulo, Piracicaba, SP, Brazil \\ ${ }^{2}$ Soil Physics Laboratory, Cena, University of Sao Paulo, Piracicaba, SP, Brazil \\ ${ }^{3}$ Agricultural Engineering Department, Universidade Federal de Pelotas, Pelotas, RS, Brazil \\ Correspondence: Felipe Fadel Sartori, Crop Science Department, Esalq, University of Sao Paulo, C.P. 9. \\ 13.418-900, Piracicaba, SP, Brazil. Tel: 55-193-429-4110. E-mail: felipefsartori@gmail.com
}

Received: July 23, 2018

doi:10.5539/jas.v10n11p158
Accepted: September 3, $2018 \quad$ Online Published: October 15, 2018

URL: https://doi.org/10.5539/jas.v10n11p158

\begin{abstract}
The West African Economic and Monetary Union (abbreviated as UEMOA from its name in French: Union Économique et Monétaire Ouest-Africaine) is an organization of eight West African countries: Benin, Burkina Faso, Ivory Coast, Guinea-Bissau, Mali, Niger, Senegal and Togo. This region suffers an agricultural yield gap mainly due to misplanning of crop zoning. Our study aimed to perform an agricultural zoning for maize and soybean in the UEMOA region based on (i) potential yield (carbon dioxide, temperature, photosynthetically active radiation, photoperiod and genotype), (ii) attainable yield, under high crop management and technology inputs and (iii) actual yield. Results show that the UEMOA region is very suitable for growing maize and soybeans; however, a large gap exists between attainable and actual yields. It is shown that the adoption of better management and technology strategies is a way to greatly increase local yields.
\end{abstract}

Keywords: Africa, yield gap, agriculture

\section{Introduction}

UEMOA, the West African Economic and Monetary Union or in French: Union Économique et Monétaire Ouest-Africaine, is an organization of eight West African countries founded to promote the economy of participating countries: Benin, Burkina Faso, Ivory Coast, Guinea-Bissau, Mali, Niger, Senegal and Togo. It presents a GPD (Gross Domestic Product) of 146 billion dollars, and a population of about 100 million people (a mixture of ethnic groups and non-African ancestries), under a French colonization history and in the lowest quartile of the HDI (Human Development Index) (Wikipedia, 2014).

The UEMOA countries are, in general, relatively un-urbanized with an average of only $36 \%$ of the population living in cities; the minimum in Niger, with $18 \%$ and the maximum in Ivory Coast with $51 \%$. All countries depend on food imports to supply their needs. In agricultural sector, the main problem is food security since the local agriculture employs low technology and the main objective is family subsistence. A pressing need exists for an increase of land productivity and employment of local labor force, aiming to ensure food security, as well as reducing the dependency of imports and external debts. One of the authors of this study completed a mission to evaluate the status of agricultural production of the area and suggest yield improvement mechanisms.

Estimates of agricultural yield can be expressed as potential yield, attainable yield and actual yield, and the respective yield gaps (Sentelhas et al., 2015). Potential yield depends solely on air carbon dioxide content, temperature, photosynthetically active radiation, photoperiod and genotype. The attainable yield is the yield achieved with best management practices on a given location. Both attainable and potential yields vary from season to season and year to year depending on meteorological factors. Understanding the existing yield gaps and identifying the most important constraints to achieving optimal yield allows prioritizing efforts in improving yield and profit. It also maximizes the return of investment in research and development.

In order to identify yield gaps, understand their causes and suggest ways to reduce them, in this study we present an agricultural zoning of the UEMOA territory, choosing as examples, maize and soybean crops, quantifying respective potential, attainable and actual yields. 


\section{Method}

\subsection{Database}

The applied methodology is based on established and known concepts of yield (Doorenbos \& Pruitt, 1975), using geoprocessing tools, computational programming and spatial modelling, similar to those described in Mueller at al. (2018). Edaphic and climatic data were combined with information of soil cover, respecting protected areas or those with preservation interest, resulting in an estimate of the potential production of maize and soybean, integrated to the dynamics of local land occupation.

Using soil maps common to all UEMOA countries, a database was constructed in a SIG environment using the software TNTMIPS, containing: (a) a digital cartographic base (hydrographic and political division), (b) soil classes, and (c) history of weather data

Data about the political division of the UEMOA territory was accessed from Thematic Mapping (2009). Soil attributes of the mapping units were based on FAO (2012), a classification that comprises natural soil fertility, texture, relief, soil depth, erosion susceptibility (slope, texture, and depth), drainage, stoniness and rockiness. Historical data of monthly and yearly rainfall, minimum, maximum and average monthly air temperature and solar radiation from the period between 1950 and 2000, were extracted from Hijmans et al. (2005a, b). These authors made a worldwide survey of the above-mentioned variables, eliminating stations that presented errors.

Pedologic data, soil water storage capacity, standardization of attributes, soil names and other soil data were obtained from FAO (2012), based on the World Reference Base for Soil Resources (WRB). Data of altitude and slope were obtained from SRTM (2010).

The climatological water balances were established through a computational routine of integrated variable processing of rainfall, temperature, solar radiation and soil water storage. This procedure allowed the calculation of water deficit and excess, potential evapotranspiration (ET0) and actual evapotranspiration (ETa).

Soil quality indexes calculation was based on soil data according to the WRB classification (FAO, 2006).

\subsection{Yield and Land Suitability Estimates}

Attainable crop yield was calculated considering a standard agronomic reference of high-input technology. The estimates of actual yield were based on the socio-economic and infrastructural conditions of the region, generating a low-input yield in which the difficulty of access to agro-chemicals or financial resources are taken into account, thus corresponding to a low level of employed technology.

The evaluation of the land suitability is a process of determining the soil aptitude for specific uses and refers to a set of basic principles and concepts that can be applied worldwide. It requires a comparison between different soil types, obtained benefits and existing needs. At a quantitative stage, levels of suitability were established: high, medium, low and not suitable. The criteria of classification can be found in Tables 1, 3 and 4 .

A production environment was defined as the sum of the interactions of soil attributes (fertility, drainage, texture and depth) and of the relief, which directly influence crop production. For this study, the methodology for production environment classification proposed by Prado (2007) was adapted to the characteristics of the available data for the region, combining suitability with respect to slope and soil type. Edaphic information was combined to relief information, and the combined quality of soil-relief was used as a logic key for suitability. Each soil presents class of land suitability for annual crops based on land slope S (Table 2). In this way, a Soil Quality Index (SQI) was calculated as the geometric mean of soil depth, drainage and combined texture-structure, each ranked from 1 to 3 (Table 1):

$$
\mathrm{SQI}=\sqrt[3]{\mathrm{a}_{1} \mathrm{a}_{2} \mathrm{a}_{3}}
$$

Where, $a_{1}$ is the score for soil depth, $a_{2}$ for drainage and $a_{3}$ for texture-structure. According to the estimated values of SQI for each soil order, four classes were established for suitability levels: Not suitable (SQI $\leq 1.3)$, Low $(1.3<\mathrm{SQI}<1.8)$, Medium $(1.8 \leq \mathrm{SQI}<2.5)$, and High $(\mathrm{SQI} \geq 2.5)$. 
Table 1. Classification of the land suitability (high, medium, low and not suitable) per soil order, with the correlation between the World Reference Base for Soils Resources-WRB (FAO, 2006), based on the soil quality index (SQI): soil depth $\left(\mathrm{a}_{1}\right)$, drainage $\left(\mathrm{a}_{2}\right)$ and texture-structure $\left(\mathrm{a}_{3}\right)$

\begin{tabular}{|c|c|c|c|c|c|c|}
\hline WRB & Initial & $a_{1}$ & $\mathrm{a}_{2}$ & $a_{3}$ & SQI & Land suitability \\
\hline Acrisol & $\mathrm{AC}$ & 3 & 2 & 2 & 2.3 & Medium \\
\hline Alissol & $\mathrm{AL}$ & & & & & \\
\hline Arenosol & AR & 2 & 3 & 1 & 1.8 & Medium \\
\hline Calcisol & CL & 2 & 1 & 3 & 1.8 & Medium \\
\hline Cambisol & $\mathrm{CM}$ & 1 & 2 & 2 & 1.6 & Low \\
\hline Chernozem & $\mathrm{CH}$ & & & & & \\
\hline Durisol & DU & 1 & 1 & 1 & 1.0 & Not suitable \\
\hline Ferrasol & FR & 3 & 3 & 2 & 2.6 & High \\
\hline Fluvisol & FL & 2 & 3 & 1 & 1.8 & Medium \\
\hline Gleysol & GL & 2 & 1 & 3 & 1.8 & Medium \\
\hline Gypsisol & GY & 2 & 1 & 2 & 1.6 & Low \\
\hline Histosol & HS & & & & & \\
\hline Kastanozem & KS & & & & & \\
\hline Leptosol & LP & 1 & 2 & 2 & 1.6 & Low \\
\hline Lixisol & LX & 3 & 2 & 3 & 2.6 & High \\
\hline Luvisol & LV & 2 & 2 & 3 & 2.3 & Medium \\
\hline Nitisol & NT & 3 & 3 & 3 & 3.0 & High \\
\hline Phaeosem & PH & 3 & 2 & 3 & 2.6 & High \\
\hline Planosol & PL & 2 & 1 & 2 & 1.6 & Low \\
\hline Plinthosol & PT & 2 & 2 & 1 & 1.6 & Low \\
\hline Podzol & PD & & & & & \\
\hline Regosol & RG & 1 & 1 & 2 & 1.3 & Not suitable \\
\hline Rock Outcrop & RK & 1 & 1 & 1 & 1.0 & Not suitable \\
\hline Solonchak & $\mathrm{SC}$ & 1 & 1 & 1 & 1.0 & Not suitable \\
\hline Solonetz & SN & 1 & 1 & 1 & 1.0 & Not suitable \\
\hline Stagnosol & ST & 1 & 1 & 1 & 1.0 & Not suitable \\
\hline Vertisol & VR & 2 & 1 & 3 & 1.8 & Medium \\
\hline
\end{tabular}

Note. * Miscellaneous (Urban-UR, Water Bodies-WR, and Dunes or Shifting Sands-DS).

Land slope was obtained based on the land elevation model in $90 \mathrm{~m}$ (SRTM, 2010). Starting from the functions in the GIS (Geographic Information System) environment and with the utilization of algorithms from eight neighboring localities, it was possible to calculate the slope in percent, as shown in Table 2.

Table 2. Classes of land suitability for annual crops based on land slope $\mathrm{S}$

\begin{tabular}{ll}
\hline Suitability class & Range of slopes (S, \%) \\
\hline High (flat relief) & $\mathrm{S} \leq 2$ \\
Medium (softly waved relief) & $2<\mathrm{S} \leq 6$ \\
Low (wavy relief) & $6<\mathrm{S} \leq 12$ \\
Not suitable (hilly relief) & $\mathrm{S}>12$ \\
\hline
\end{tabular}

The conjunction of SQI, which considers the land suitability, with the slope suitability (Table 2), yielded a general classification of the production environment, subdivided into nine classes (Table 3). 
Table 3. Classification of production environments $\left(A_{1}, A_{2}, B_{1}, B_{2}, C_{1}, C_{2}, D_{1}, D_{2}, E_{1}\right.$, and not suitable) considering SQI and slope

\begin{tabular}{lllll}
\hline \multirow{2}{*}{ Slope class } & \multicolumn{4}{c}{ Class } \\
\cline { 2 - 5 } & High & Medium & Low & Not suitable \\
\hline High & $\mathrm{A}_{1}$ & $\mathrm{~B}_{1}$ & $\mathrm{C}_{2}$ & Not suitable \\
Medium & $\mathrm{A}_{2}$ & $\mathrm{~B}_{2}$ & $\mathrm{D}_{2}$ & Not suitable \\
Low & $\mathrm{C}_{1}$ & $\mathrm{D}_{1}$ & $\mathrm{E}_{1}$ & Not suitable \\
Not suitable & Not suitable & Not suitable & Not suitable & Not suitable \\
\hline
\end{tabular}

Note. Among the classes considered suited, $\mathrm{A}_{1}$ refers to the best productivity and $\mathrm{E}_{1}$ to the worst.

The soil classes found in the UEMOA territory (Figure 1) show that the region including South Niger, center south Mali, center north Burkina Faso and north Senegal, denominated by the Sahel belt, is covered by an extensive and wide band of Arenosols which, in the north direction, in Niger and Mali, is substituted by desert dunes of large areas of Leptosols and soils of calcitic origin (Calcisols), gypsite (Gypsisols) and rocky outbreaks.

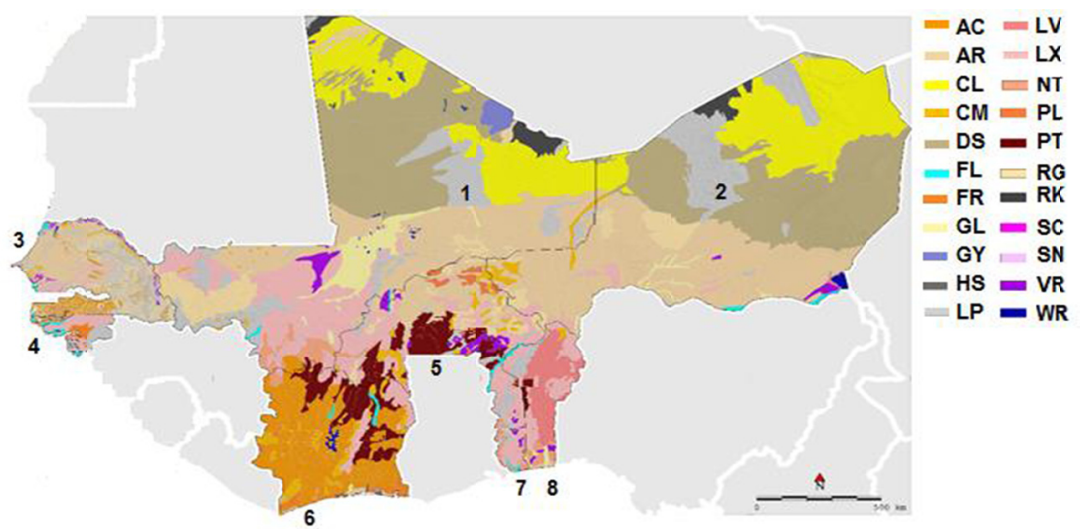

Figure 1. Soil map of the UEMOA territory, obtained through the classification of WRB (FAO, 2006) (Table 1). (1) Mali, (2) Niger, (3) Senegal, (4) Guinea Bissau, (5) Burkina Faso, (6) Ivory Coast, (7) Togo and (8) Benin

The north of parallel $15^{\circ} \mathrm{N}$ is predominantly characterized by flatland of rocky soils not well developed (Regosols and Cambisols) and sand dunes, crossed by saline soils and gypsum accumulation (Solonchaks and Gypsisols). Stony soils were formed where some sort of vegetation allowed a certain weathering in situ, and the saline soils covered rocks by the evaporation of ancient lakes.

South of the Sahel band, a region of south Mali, Burkina Faso, Togo and Benin, a predominance of Lixisols is found. Ivory Coast has also its major part covered by Lixisols, but in this case, they are the Acrisols, present together with large areas of Plinthosols, that cover central-south Burkina Faso and central Benin. Togo has its territory almost completely covered by Lixisols and Luvisols.

In Guinea Bissau, there are large areas with Lixisols and Acrisols associated with Leptosols, while Senegal presents several soil types, like a mosaic but with the predominance of Arenosols and Lixisols and Acrisols.

\subsection{Potential Yield Estimation}

To estimate the potential yield $(\Gamma)$ for maize and soybean crops, the model proposed by Doorenbos and Pruitt (1975) was used, considering the following parameters: (i) radiation use efficiency, (ii) light extinction coefficient, (iii) basal temperature (optimum, maximum and minimum), (iv) metabolism type, (v) plant life cycle, (vi) harvest index, (vii) water content in the exported plants part, (viii) average air temperature, (ix) global solar radiation, (x) dry matter accumulation during cloudy and clear days, and (xi) correction factors for the leaf area index and temperature. To process these data, a computational routine was developed in the Microsoft Visual Basic (VBP, version 6.0) programing language, which simulates the growth of the crops sown each month of the year, in order to select the cycle that results in the highest yield. It is important to state that the climatologic data (solar radiation, temperature and rainfall) used in this process are average values of 50 years. 
The assimilation of $\mathrm{CO}_{2}\left(\varepsilon, \mathrm{kg} \mathrm{ha}^{-1} \mathrm{~h}^{-1}\right)$ by plants for the gross production of carbohydrate $\left(\eta, \mathrm{kg} \mathrm{ha}^{-1} \mathrm{~d}^{-1}\right.$ of $\left.\mathrm{CH}_{2} \mathrm{O}\right)$ is related to the fraction of the photosynthetically active radiation $\left(\Omega, \mathrm{J} \mathrm{m}^{-2} \mathrm{~s}^{-1}\right)$, according to:

$$
\mathrm{CO}_{2}+\mathrm{H}_{2} \mathrm{O} \stackrel{\Omega}{\rightarrow} \mathrm{CH}_{2} \mathrm{O}+\mathrm{O}_{2}
$$

The $\mathrm{CO}_{2}$ assimilation by $\mathrm{C}_{3}$ (soybean) and $\mathrm{C}_{4}$ (maize) plants correspond to the $\mathrm{CO}_{2}$ concentration of $340 \mathrm{ppm}$ (Co, ppm), can be described (Goudriaan, 1982) as:

$$
\varepsilon=\lambda\left[1-e^{-\delta \frac{\Omega(1-p)}{\lambda}}\right]\left[1+\beta \ln \left(\frac{C x}{C o}\right)\right]
$$

Where, $C x$ is the current atmospheric carbon concentration (assumed as $C x=385 \mathrm{ppm}$ ), $C o$ is the base carbon concentration, and $p$ is the crop reflection coefficient $\left(\mathrm{J} \mathrm{J}^{-1}\right) . \delta$ and $\beta$ are empirical parameters, $\delta=0.48 \mathrm{~kg}\left[\mathrm{CO}_{2}\right]$ $\mathrm{ha}^{-1} \mathrm{~h}^{-1}\left(\mathrm{~J} \mathrm{~m}^{-2} \mathrm{~s}^{-1}\right)^{-1}$ and $\beta=0.8$ for $\mathrm{C}_{3}$ species and $\beta=0.4$ for $\mathrm{C}_{4}$ species, according to Penning de Vries et al. (1983). $\lambda\left(\mathrm{kg} \mathrm{ha}^{-1} \mathrm{~h}^{-1}\right)$ is an auxiliary variable calculated according to:

$$
\lambda=40\left(w_{0}+\frac{w_{1}}{w_{2}}\right) T
$$

Where, $T\left({ }^{\circ} \mathrm{C}\right)$ refers to air temperature; and $w_{0}, w_{1}$ and $w_{2}$ to parameters linked to air temperature (Table 4) (Goudriaan, 1982).

Table 4. Empirical parameters depending on air temperature to obtain auxiliary variable $\lambda$ (Goudriaan, 1982)

\begin{tabular}{llll}
\hline Temperature range $\left(\right.$ in $\left.{ }^{\circ} \mathrm{C}\right)$ & $\mathrm{w}_{0}$ & $\mathrm{w}_{1}$ & $\mathrm{w}_{2}$ \\
\hline $\mathrm{T}<0$ & 0.0 & 0.0 & 50 \\
$0 \leq \mathrm{T}<20$ & 0.0 & 0.3 & 10 \\
$20 \leq \mathrm{T}<30$ & -0.2 & 0.2 & 5 \\
$30 \leq \mathrm{T}<35$ & 1.0 & 0.0 & 5 \\
$35 \leq \mathrm{T}<40$ & 2.4 & -0.2 & 5 \\
$40 \leq \mathrm{T}<50$ & 4.0 & -0.4 & 5 \\
$\mathrm{~T} \geq 50$ & 0.0 & 0.0 & 50 \\
\hline
\end{tabular}

Considering the gross mass of carbohydrates produced on a daily average basis for the whole growth cycle, estimated from the number of degree-days from plant emergence to flowering $\left(G D_{f},{ }^{\circ} \mathrm{C} d\right)$ and from the length of the reproductive phase $\left(D_{R}, \mathrm{~d}\right)$ knowing the average photoperiod of the cycle $\left(H, \mathrm{~h} \mathrm{~d}^{-1}\right)$ and the average leaf area index of the cycle $\left(\mathrm{I}_{\mathrm{LA}}, \mathrm{m}^{2}[\right.$ leaf $] \mathrm{m}^{-2}$ [soil] $)$, the total carbon productivity $\left(\Psi, \mathrm{kg}\left[\mathrm{CO}_{2}\right]\right.$ ha $^{-1}$ [soil] $)$ can be estimated using the equations:

$$
\begin{gathered}
\mathrm{C}=\frac{G D_{f}}{\left(T-T_{b}\right)}+D_{R} \\
\Psi=A_{d c} \cdot I_{L A} \cdot C \cdot H
\end{gathered}
$$

Where, $A_{d c}\left(\mathrm{~kg}\left[\mathrm{CO}_{2}\right] \mathrm{ha}^{-1}[\mathrm{leaf}] \mathrm{h}^{-1}\right)$ is the carbon dioxide assimilation, $\mathrm{Tb}\left({ }^{\circ} \mathrm{C}\right)$ is the base temperature for crop development and $T\left({ }^{\circ} \mathrm{C}\right)$ is the average air temperature. Considering the very low latitudes, photoperiod $H$ was set to $12 \mathrm{~h}$.

To transform $\Psi$ in dry matter of the different plant organs (root, stalk or stem, leaf and grain), some corrections ( $C_{R M C}$ and $C_{P A R}$ maintenance and growth respiration and photosynthetic active radiation coefficients, respectively) were used according to the principles presented by De Wit $(1965,1978,1982)$, developed to estimate the potential yield of a crop through the available energy of the considered locality and experimental data presented by Doorenbos and Kassam (1979), calibrated for a wide range of climatic conditions.

$$
\Gamma=\frac{30}{40} \cdot \frac{\Psi \cdot C_{R M C} \cdot C_{P A R} \cdot E_{C D M} \cdot H I}{1-u}
$$

Where, $\Gamma\left(\mathrm{kg}\right.$ [wet botanical seed] $\left.\mathrm{ha}^{-1}\right)$ is the potential productivity, $E_{C D M}\left(\mathrm{~kg}\right.$ [dry matter] $\mathrm{kg}^{-1}$ [carbohydrate] $)$ is the efficiency of converting carbohydrate in dry matter, $H I$ ( $\mathrm{kg}$ [dry botanical seed] $\mathrm{kg}^{-1}$ [dry matter]) is the harvest index, and $u\left(\mathrm{~kg}\right.$ [water] $\mathrm{kg}^{-1}$ [wet botanical seed]) is the seed water content. 


\subsection{Attainable Yield Estimation}

Attainable yield $\left(\Theta, \mathrm{kg} \mathrm{ha}^{-1}\right)$ can be estimated from potential yield $\left(\Gamma, \mathrm{kg} \mathrm{ha}^{-1}\right)$ applying reduction factors for drought stress, nutrient availability, management practices, and soil quality including depth, drainage, texture and structure, considering a high technology input condition according to Doorenbos and Pruitt (1975):

$$
\Theta=\Gamma \cdot \sum_{i=1}^{3}\left(\frac{E T a_{a}}{E T o_{i} \cdot K c_{i}}\right)^{\Phi_{i}} \cdot \varphi
$$

Where, water stress is quantified by the ratio between actual evapotranspiration $\left(\mathrm{ET}_{\mathrm{a}}\right)$ and crop potential evapotranspiration $\left(\mathrm{ETc}=\mathrm{ET}_{0} \cdot \mathrm{Kc}\right) . \mathrm{ET}_{\mathrm{a}}$ was calculated following the Thornthwaite and Mather $(1955,1957)$ water balance method using an effective rooting depth $(\mathrm{cm})$ together with a specific capacity of soil water retention $\left(\mathrm{mm} \mathrm{cm}^{-1}\right) . \Phi$ is a reduction factor taking into account productivity factors (water and nutrients) and $\varphi$ is a depletion factor for productivity related to soil quality and relief.

The growth model was run for 12 scenarios, each one starting in one of the months of the year. The starting month resulting in the highest yield was considered to correspond to the attainable yield $\Omega$.

Once $\Gamma$ was evaluated, the actual yield $\Omega$ was obtained introducing depletion factors related to the water and nutrient availabilities, production environment and management restrictions (weeds, pests and diseases), under conditions of low employment of technologies (Doorenbos \& Pruitt, 1975; Doorenbos \& Kassam, 1979).

\section{Results and Discussion}

Topography is a key factor in the formation of soils and has a large influence on the local climate, on vegetation, and on water movement. In Figure 2, the relief of the UEMOA territory is mapped. Regions around parallel $20^{\circ} \mathrm{N}$, of Niger and Mali present the highest altitudes with peaks above 1,000 $\mathrm{m}$ (Jones et al., 2013).

Soil physical suitability is low in many parts of the territory, with $32 \%$ of the land considered not suitable for agriculture (Figure 3). Mainly parts of Mali and Niger, north of parallel $15^{\circ} \mathrm{N}$. Another $5 \%$ are considered of low suitability, located in southeast Mali, southeast Senegal, inner part of Ivory Coast, Togo and Benin and in the saline soils of Niger and Mali. Areas with medium suitability are found in 19\% of the territory and intermingle with areas of moderate and high suitability in the proportion of 32 and $12 \%$, respectively.

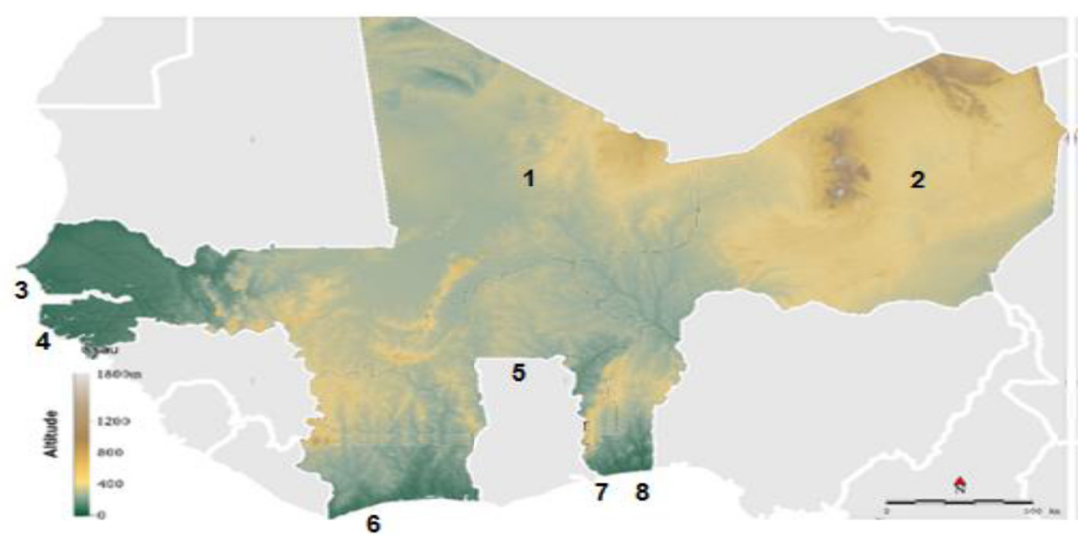

Figure 2. Relief in the UEMOA territory. (1) Mali, (2) Niger, (3) Senegal, (4) Guinea Bissau, (5) Burkina Faso, (6) Ivory Coast, (7) Togo and (8) Benin 


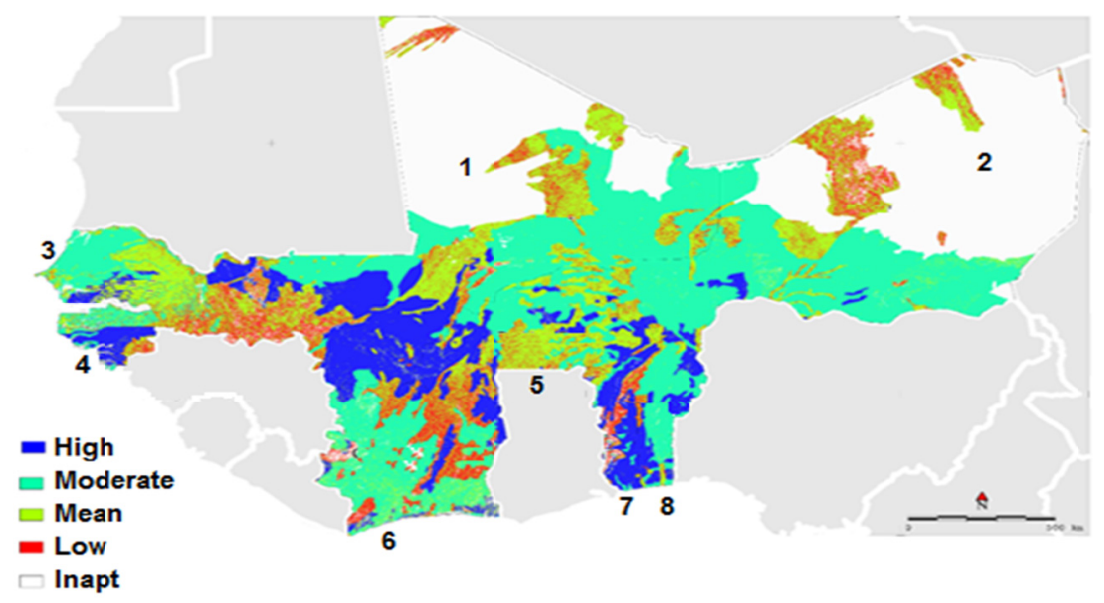

Figure 3. Production environments in the UEMOA territory. (1) Mali, (2) Niger, (3) Senegal, (4) Guinea Bissau, (5) Burkina Faso, (6) Ivory Coast, (7) Togo and (8) Benin

The world maize production was 1,018 billion tons according to FAO (2015), with USA as the largest producer with $34.7 \%$ of this amount. Africa is responsible for $7 \%$ and imports about $20 \%$ of all the consumed maize in the continent. Practically all maize produced in Africa is cultivated as a dryland crop, which represents a great consequence from the social point of view in years of rainfall deficiency and or bad distribution. While the total world production of maize is cultivated on 185 million hectares of land, the completely African production covers 35 million hectares (IITA, 2014a).

The UEMOA contribution to the 2013 African maize production was only $8.5 \%$ of the maize produced in the continent (FAO, 2015). Table 5 shows details of this contribution.

Table 5. Maize yield, harvested area and average productivity of the countries of the UEMOA, Africa and Brazil, for 2013 (FAO, 2015)

\begin{tabular}{llll}
\hline Country & Maize yield $\left(10^{6}\right.$ tons $)$ & Harvested area $(\mathrm{ha})$ & Average productivity $\left(\mathrm{kg} \mathrm{ha}^{-1}\right)$ \\
\hline Benin & 1,346 & 973,453 & 1,382 \\
Burkina Faso & 1,585 & 913,630 & 1,735 \\
Ivory coast & 661 & 340,000 & 1,944 \\
Guinea Bissau & 7 & 15,000 & 488 \\
Mali & Mali & 1,503 & 640,526 \\
Niger & Niger & 12 & 15,000 \\
Senegal & Senegal & 223 & 151,450 \\
Togo & Togo & 693 & 550,000 \\
UEMOA & 6,154 & $3,599,059$ & 1,433 \\
Africa & 71,613 & $34,903,210$ & 2,033 \\
Brazil & 80,539 & $15,317,432$ & 5,258 \\
\hline
\end{tabular}


Table 6. $\mathrm{N}, \mathrm{P}_{2} \mathrm{O}_{5}$ and $\mathrm{K}_{2} \mathrm{O}$ fertilizer consumption in 2012 in the UEMOA countries, in Africa and in Brazil (FAO, 2015)

\begin{tabular}{llll}
\hline \multirow{2}{*}{ Country } & \multicolumn{3}{c}{ Total fertilizer consumption (metric tons in 2012) } \\
\cline { 2 - 4 } & $\mathrm{N}$ & $\mathrm{P}_{2} \mathrm{O}_{5}$ & $\mathrm{~K}_{2} \mathrm{O}$ \\
\hline Benin & 28,893 & 14,247 & 9,340 \\
Burkina Faso & 28,253 & 18,696 & 19,037 \\
Ivory Coast & 33,526 & 15,264 & 24,856 \\
Guinea Bissau & unavailable & Unavailable & unavailable \\
Mali & 126,927 & 31,659 & 21,108 \\
Niger & 12,932 & 3,211 & 5,026 \\
Senegal & 20,741 & 1,742 & 4,381 \\
Togo & 6,797 & 5,466 & 998 \\
UEMOA & 257,969 & 90,285 & 84,746 \\
Africa & $3,279,477$ & $1,394,159$ & 522,916 \\
Brazil & $4,251,169$ & $4,343,221$ & $4,600,684$ \\
\hline
\end{tabular}

Another great challenge related to agricultural activities is the informality of the Land Registry. Land ownership is commonly assigned to the population by customary use, under the influence and agreement of local leaders, but there is no documentation or centralized records to ensure legal certainty in the transfer of ownership of the land. Due to the resulting small size of the properties it is difficult to implement efficient agricultural management over larger areas. The result is a large yield gap, i.e., the actual yield is only a fraction of potential and attainable yields.

From the point of view of technological adoption, FAO (2015) data based on the response of local farmers to questionnaires show that the consumption of agricultural inputs in UEMOA member countries is very low. Regarding fertilizers, there are only the data of total consumption by countries, which hinders the understanding of the adopted technology level by each crop. However, based on the average productivity presented for maize cultivation (Table 5) it appears that there is very low technological input in the cultivation of this grain.

The fertilizer volumes consumed by the countries of UEMOA in 2012 can be seen in Table 6 . The consumption of nitrogen, phosphorus and potassium across the African continent represent $2.7 \%, 3.0 \%$ and $1.8 \%$ of the world fertilizer consumption respectively. In Brazil alone, domestic consumption is $3.6 \%, 9.4 \%$ and $16.15 \%$ of the world total.

The three largest consumers of fertilizers in Africa are Egypt, South Africa and Ethiopia, and within UEMOA it is Mali, which consumes 2 to $4 \%$ of all fertilizer consumed on the African continent.

The world production of soybeans in 2013, according to FAO (2015) was 276 million tons; the United States was the largest producer, accounting for $32 \%$ of this total. Africa produces less than $1 \%$ of the world total, and imports of grain are close to the total production (IITA, 2014b), about 2.2 million tons in 2013. The largest producer of soybeans in the African continent is South Africa, followed by Nigeria, both account for $62 \%$ of all soybeans produced in this continent.

Table 7. Soybean yield, harvested area and average productivity of the countries of the UEMOA, Africa and Brazil, for 2013 (FAO, 2015)

\begin{tabular}{llll}
\hline Country & Soybean yield $\left(10^{6}\right.$ tons $)$ & Harvested area $($ ha $)$ & Average productivity $\left(\mathrm{kg} \mathrm{ha}^{-1}\right)$ \\
\hline Benin & 16,000 & 19,000 & 842 \\
Burkina Faso & 22,773 & 16,114 & 1,351 \\
Ivory coast & 1,000 & 950 & 1,052 \\
Guinea Bissau & unavailable & Unavailable & unavailable \\
Mali & 1,850 & 2,750 & 672 \\
Niger & unavailable & Unavailable & unavailable \\
Senegal & unavailable & Unavailable & unavailable \\
Togo & 1,500 & 3,000 & 500 \\
UEMOA & 42,123 & 41,814 & 1,007 \\
Africa & $2,246,313$ & $1,797,259$ & 1,797 \\
Brazil & $81,724,477$ & $27,906,675$ & 2,929 \\
\hline
\end{tabular}




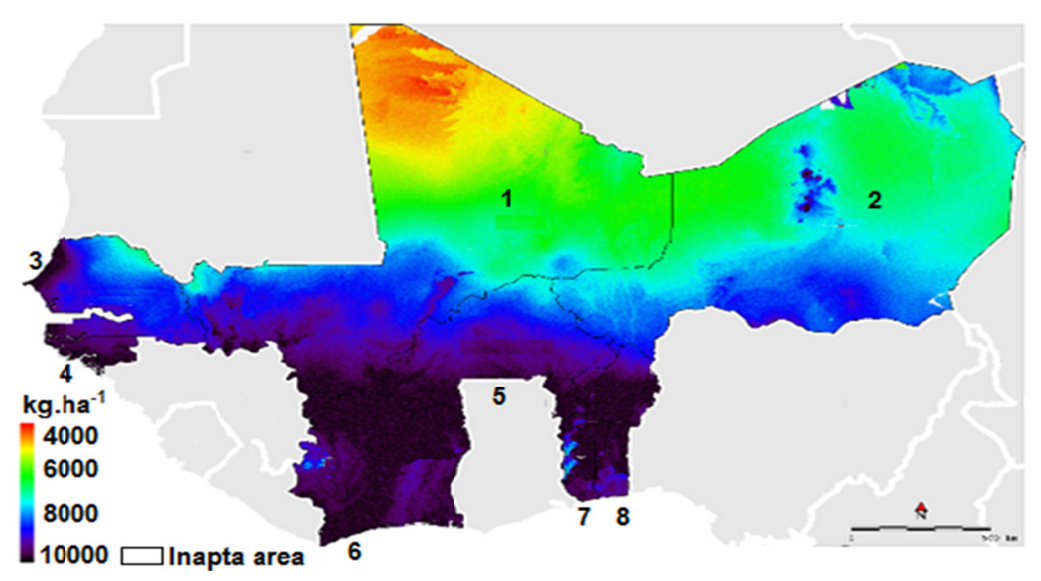

(A) Soybean

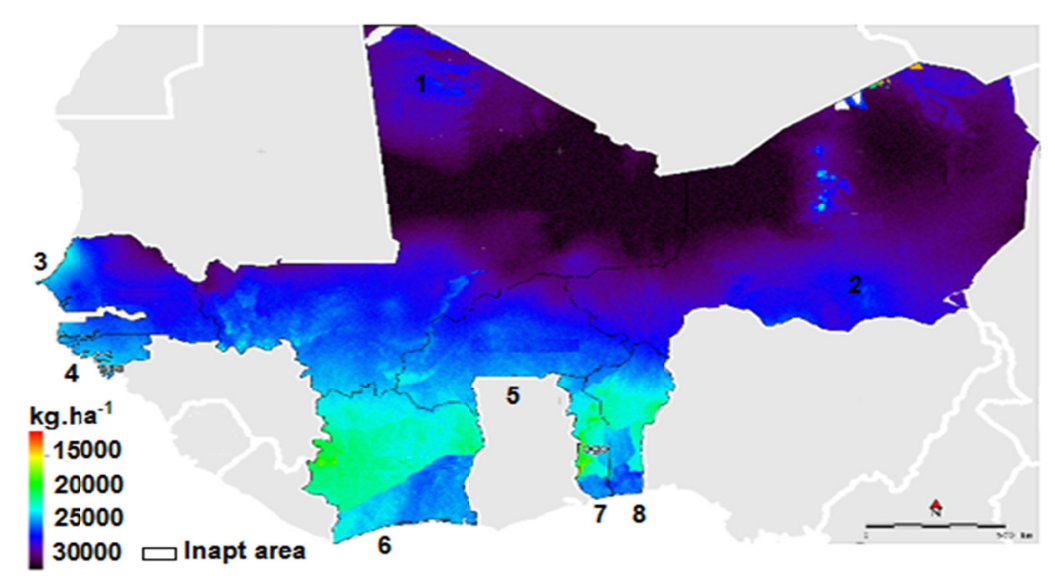

(B) Maize

Figure 4. Potential yield $\left(\mathrm{kg} \mathrm{ha}^{-1}\right)$ for soybean (A) and maize (B) in the UEMOA territory. (1) Mali, (2) Niger, (3) Senegal, (4) Guinea Bissau, (5) Burkina Faso, (6) Ivory Coast, (7) Togo and (8) Benin

As can be seen in Table 7, Burkina Faso is the largest soybean producer in the UEMOA, with 22 million tons of soybeans produced from 16,000 hectares. Most harvested soybean area is in Benin, but with very low productivity levels (FAO, 2015).

Maize and soybean are widely studied species, making possible the estimation of potential yield (Figure 4) from a deterministic model of crop growth.

The resulting map of estimated potential yield for maize crop in UEMOA is shown in Figure 4A, with values greater than $25,000 \mathrm{~kg} \mathrm{ha}^{-1}$. However, the region with the highest yield potential, with more than $30,000 \mathrm{~kg} \mathrm{ha}^{-1}$ is located to the north of the parallel $15^{\circ} \mathrm{N}$, the region facing serious cropping restrictions. The coastal region of the countries bordering the Atlantic has the lowest production potential for this grass, but still at high levels, reaching $20,000 \mathrm{~kg} \mathrm{ha}^{-1}$.

Figure 4B shows that UEMOA territory is very favorable for soybeans production, with potential yield above $4,000 \mathrm{~kg} \mathrm{ha}^{-1}$. The region with the greatest potential, above $10,000 \mathrm{~kg} \mathrm{ha}^{-1}$, is located southern of parallel $15^{\circ} \mathrm{N}$. Towards the north of parallel $15^{\circ} \mathrm{N}$, the potential soybean yield is reduced gradually, reaching lower levels, near $5,000 \mathrm{~kg} \mathrm{ha}^{-1}$ north of Mali; region with higher water restrictions from the standpoint of evapotranspiration.

The attainable yield of maize and soybean (Figure 5) was calculated through a deterministic model of crop growth which consisted of determining the potential yield taking into consideration depletion limitations by water and nutrients, loss factors related to the incidence of insect pests, diseases and weeds, difficulties imposed by the steepness of the terrain and soil constraints, however, adopting a usage scenario of good agronomic practices under a high use of technology. 


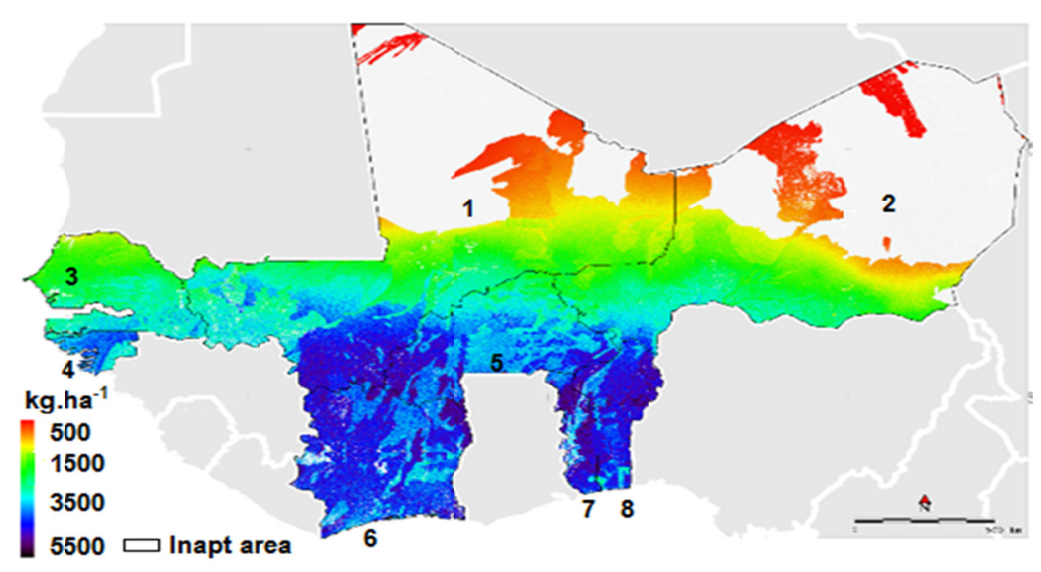

(A) Soybean

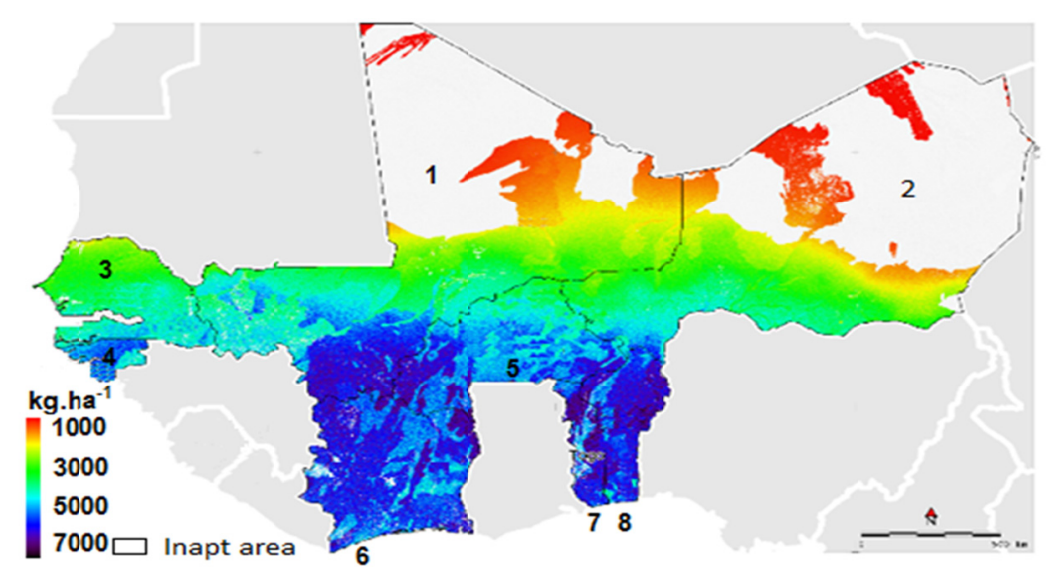

(B) Maize

Figure 5. Attainable yield $\left(\mathrm{kg} \mathrm{ha}^{-1}\right)$ for soybean (A) and maize (B) in the UEMOA territory. (1) Mali, (2) Niger, (3) Senegal, (4) Guinea Bissau, (5) Burkina Faso, (6) Ivory Coast, (7) Togo and (8) Benin

The attainable yield map of the maize crop (Figure 5B) shows that the water availability in the UEMOA region is the major factor in reducing the estimated potential yield. The attainable yield trend shows up in inverse proportion to the potential yield, i.e., in regions where potential yield was higher, attainable is the lowest. In north of latitude $15^{\circ} \mathrm{N}$, an arid desert region, the potential yield reached more than $30,000 \mathrm{~kg} \mathrm{ha}^{-1}$, while the attainable was less than $1,000 \mathrm{~kg} \mathrm{ha}^{-1}$, because of the serious water restrictions dominating the region.

Guinea Bissau, Ivory Coast, extreme south of Mali, Burkina Faso, Togo and Benin are countries that show more potential for maize cultivation in rainfed conditions. Clearly, the adoption of higher technology interventions by these countries would require surveys on a smaller scale in order to obtain a better mapping of local growing conditions.

The attainable yield map of the soybean crop is shown in Figure 5B, in which it is observed that for the UEMOA region there is a geospatial trend for potential yield; unlike of what occurred in the estimation of yield for maize cultivation.

The area north of the $15^{\circ} \mathrm{N}$ parallel, with arid climate, is the region with the lowest achievable yields, depending on the serious dominant water restriction in that locality.

In the transition between the arid and tropical region, in the range between $12^{\circ} 30^{\prime} \mathrm{N}$ and $10^{\circ} \mathrm{N}$, the achievable yields oscillate between 1,500 and $3,000 \mathrm{~kg} \mathrm{ha}^{-1}$, which can be considered quite interesting. This yield reached southern latitude $10^{\circ} \mathrm{N}$.

In general, the attainable yield of soybean is quite feasible with current levels and we can list the countries of Guinea Bissau, southern Mali, Ivory Coast, Burkina Faso, Togo and Benin to be considered as strong candidates 
for the cultivation of this legume, with attainable yield levels exceeding $3,000 \mathrm{~kg} \mathrm{ha}^{-1}$. It is also noteworthy that the countries and regions suitable for growing maize under dryland conditions are those where soybean cultivation is shown feasible from a technical point of view, they are: Guinea Bissau, southern Mali, Ivory Coast, Burkina Faso, Togo and Benin.

The estimated actual yield of maize and soybean (Figure 6) was calculated from the estimated potential yield (Figure 5) with depletion limitations (Figure 4).

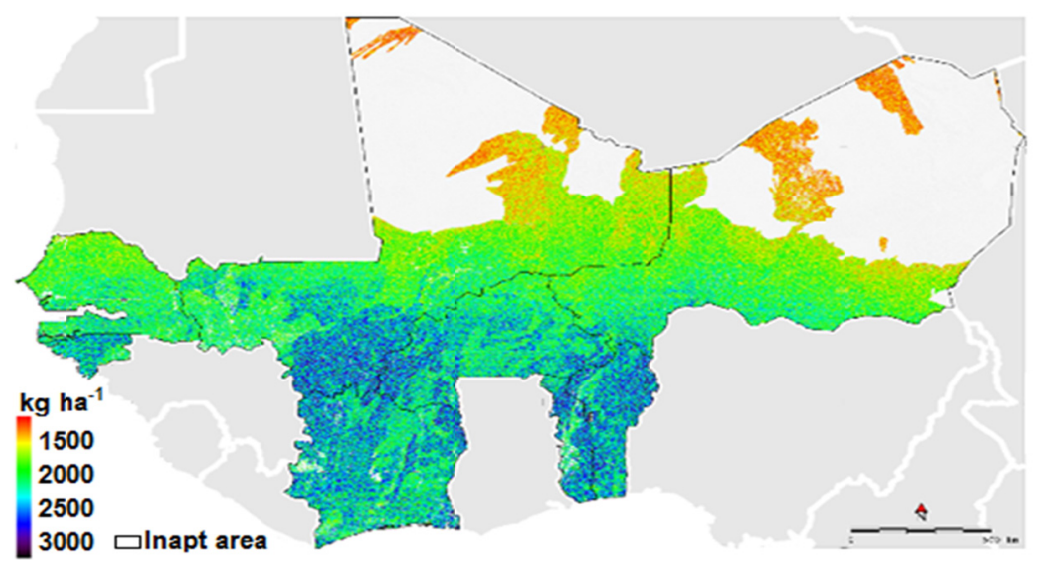

(A) Soybean

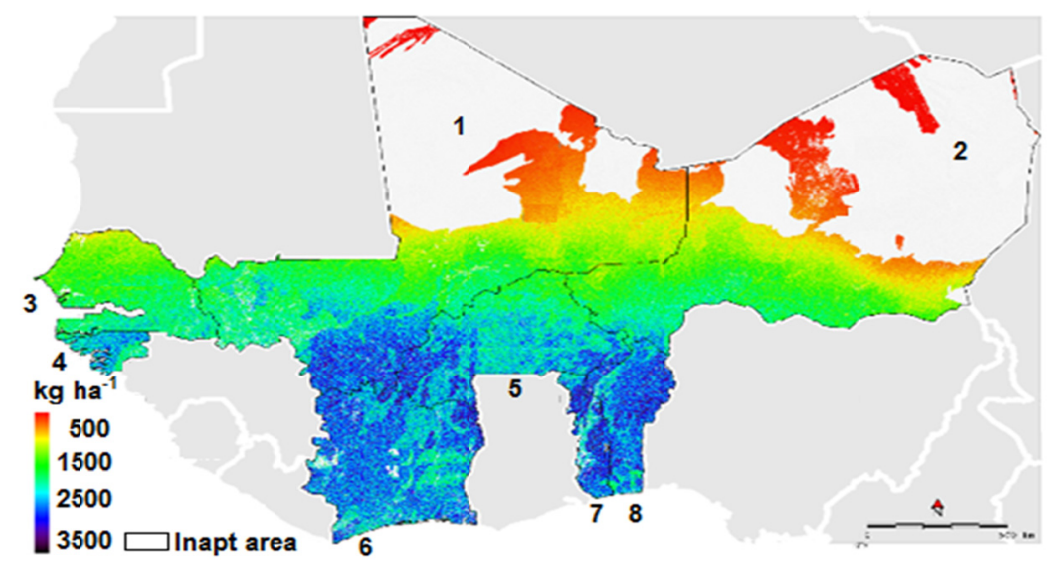

(B) Maize

Figure 6. Actual yield $\left(\mathrm{kg} \mathrm{ha}^{-1}\right)$ for soybean (A) and maize (B) in the UEMOA territory. (1) Mali, (2) Niger, (3) Senegal, (4) Guinea Bissau, (5) Burkina Faso, (6) Ivory Coast, (7) Togo and (8) Benin

The actual yield of maize (Figure $6 \mathrm{~B}$ ) varied from 500 to $3,000 \mathrm{~kg} \mathrm{ha}^{-1}$, which can be considered adequate in view of the yield levels found in the African continent, with an average of 2,033 $\mathrm{kg} \mathrm{ha}^{-1}$ in 2013, while in Brazil it was $5,258 \mathrm{~kg} \mathrm{ha}^{-1}$ (FAO, 2015).

The actual yield map follows a similar geospatial distribution trend of the attainable yield map, with countries located north of parallel $15^{\circ} \mathrm{N}$, considered arid region recording lower yield levels (less than $500 \mathrm{~kg} \mathrm{ha}^{-1}$ ) ; those located between parallels $15^{\circ} \mathrm{N}$ and $12^{\circ} 30^{\prime} \mathrm{N}$, of semi-arid climatic range, recording approximate yield levels of $1,500 \mathrm{~kg} \mathrm{ha}^{-1}$, and those south of $10^{\circ} \mathrm{N}$ parallel $\mathrm{N}$, the tropical region, the best yield levels, ranging between 2,500 and $3,500 \mathrm{~kg} \mathrm{ha}^{-1}$.

Soybean actual yield shown in Figure 6A also presents the same geospatial tendency of the potential and attainable yields. The area north of parallel $15^{\circ} \mathrm{N}$ indicates the lowest average values, of the order of $500 \mathrm{~kg} \mathrm{ha}^{-1}$, due to the serious hydric restriction. However, from parallel $15^{\circ}$ to $12^{\circ} 30^{\prime} \mathrm{N}$, the semiarid band, the actual yield 
levels reach $1,000 \mathrm{~kg} \mathrm{ha}^{-1}$, and below that area 2,000 $\mathrm{kg} \mathrm{ha}^{-1}$. The average actual yield of soybean in Brazil is $2,920 \mathrm{~kg} \mathrm{ha}^{-1}$ and in Africa about $1,800 \mathrm{~kg} \mathrm{ha}^{-1}$.

Considering the relative land use as a gauge of economic activity, Burkina Faso is the country with the highest utilization of the territory with agricultural activities (65\%) followed by Senegal (56\%). Other countries have less than $50 \%$ of the territory covered by agricultural activities, and UEMOA, in general, only $18 \%$. It is important to remember that Niger and Mali have $72 \%$ and $65 \%$ of their territories covered by dunes or areas without vegetation; in general, the territory of the UEMOA has $50 \%$ of its territory in the same condition.

Despite the excellent weather conditions prevailing in approximately half of the territory formed by the UEMOA, the actual yields of the maize and soybean crops are considered low, which conflicts with the simulated high potential and attainable yields. Apparently the reduced use of technologies is the major factor in this regard, explained by the low level of economic and social development of the region, the incipient supply chain of inputs and inadequate technology combined with the low purchasing power of local farmers and a lack of regulatory policies to implement agricultural activity in the region.

The simulated actual yield levels in this study are quite relevant and comparable to the yield data collected by FAO (2015) in each country, however, it is important to mention that the attainable yield levels, although realistic, are still far from the reality of this region.

The territory of the countries belonging to UEMOA, Mali, Niger, Senegal, Guinea Bissau, Burkina Faso, Ivory Coast, Togo and Benin are presented in relation to agricultural zoning: (i) about $50 \%$ of the area can be considered as not suitable for maize and soybeans, primarily due climatic and pedologic restrictions, as well as environmental, or even being occupied by urban centers; (ii) from the point of view of pedologic evaluation, these countries are in relatively flat areas of higher altitude and present restrictions for agriculture due to the climatic conditions of extreme aridity. Regarding soil classification and land suitability: there is large spatial variability; (iii) the average values of actual yield for maize and soybean are lower than the attainable yields indicating that the main local problem is the low level of technology; (iv) for maize and soybeans, the highest attainable yield in the UEMOA region lies in the southern part of latitudes below $15^{\circ} \mathrm{N}$; and (v) local government should support programs that ensure to small farmers access to better technologies and market models that could better remunerate agricultural activities.

\section{References}

De Wit, C. T. (1965). Photosynthesis of leaf canopies. Agricultural Research Reports, 663, 1-57.

De Wit, C. T. (1978). Simulation of assimilation, respiration and transpiration of crops. Centre for Agricultural Publishing and Documentation, Wageningen, Netherlands.

De Wit, C. T. (1982). Simulation of living systems. Simulation of Plant Growth \& Crop Production, 8(4), 4517-4530.

Doorenbos, J., \& Kassam, A. H. (1979). Yield response to water. Irrigation and Drainage Paper, $33,257$.

Doorenbos, J., \& Pruitt, W. O. (1975). Guidelines for predicting crop water requirements. Irrigation and Drainage Paper, 24.

FAO (Food and Agriculture Organization of the United Nations). (2006). World reference base for soil resources: A framework for international classification, correlation and communication. World Soil Resources Reports, 103 (p. 145). Rome.

FAO (Food and Agriculture Organization of the United Nations). (2012). Harmonized world soil database: Version 1.2 (p. 50). Vienna: International Institute for Applied Systems Analysis; ISRIC-World Soil Information; Institute of Soil Science; Chinese Academy of Sciences; Joint Research Centre of the European Commission.

FAO (Food and Agriculture Organization of the United Nations). (2015). FAO Statistics Division. Retrieved March 17, 2015, from http://faostat3.fao.org/download/Q/QC/E

Goudriaan, J. (1982). Potential productivity process. In F. W. T. Penning de Vries, \& H. H. van Laar, (Eds.). Simulation of plant growth and crop production (pp. 98-113). Wageningen: Pudoc.

Hijmans, R. J., Cameron, S. E., Parra, J. L., Jones, P. G., \& Jarvis, A. (2005b). Very high resolution interpolated climate surfaces for global land areas. International Journal of Climatology, 25(15), 1965-1978. https://doi.org/10.1002/joc.1276 
Hijmans, R. J., Cameron, S., Parra, J., Jones, P., Jarvis, A., \& Richardson, K. (2005a). World Clim-Global Climate Data. Free Climate Data for Ecological Modeling and GIS.

IITA (International Institute of Tropical Agriculture). (2014a). Retrieved October, 2014, from http://www.iita. org/maize

IITA (International Institute of Tropical Agriculture). (2014b). Retrieved March 17, 2015, from http://www.iita. org/soybean

ISRIC (International Soil Reference and Information Centre). (2001). Major soils of the world: World reference base for soil resources. Retrieved January 19, 2015, from http://www.isric.org/isric/webdocs/docs// major_soils_of_the_world/start.pdf

Jones, A., Breuning-Madsen, H., Brossard, M., Dampha, A., Deckers, J., Dewitte, O., ... Le Roux, P. (2013). Soil Atlas of Africa (p. 176). European Commission, Publications Office of the European Union, Luxembourg.

Müller, M. S., Dourado-Neto, D., Timm, L. C., Reichardt, K., Sartori, F. F., \& Felisberto, G. (2018). Climate analysis for agricultural improvement of the Economic Community of West African States according to Köppen and Thornthwaite. African Journal of Agricultural Research, 13(23), 1198-1212. https://doi.org/ 10.5897/AJAR2018.13064

Penning de Vries, F. W. T., Van Laar, H. H., \& Chardon, M. C. M. (1983). Bioenergetics of growth of seeds, fruits and storage organs. Proc. Symp. Potential Productivity of Field Crops under Different Environments (pp. 37-59). IRRI Los Banos, The Philippines.

Prado, H. D. (2007). Pedologia fácil: Aplicações na agricultura (p. 180). Piracicaba: FUNEP.

Sentelhas, P. C., Battisti, R., Câmara, G. M. S., Farias, J. R. B., Hampf, A. C., \& Nendel, C. (2015). The soybean yield gap in Brazil-magnitude, causes and possible solutions for sustainable production. The Journal of Agricultural Science, 153(08), 1394-1411. https://doi.org/10.1017/S0021859615000313

SRTM (Shuttle Radar Topography Mission). (2010). U.S. Geological Survey. U.S. Department of the Interior. Retrieved January 20, 2015, from http://srtm.usgs.gov

Thornthwaite, C. W., \& Mather, J. R. (1955). The water balance (No. 551.57 T515w). Laboratory of Climatology, Drexel Institute of Technology, Centerton, NJ.

Thornthwaite, C. W., \& Mather, J. R. (1957). Instructions and tables for computing potential evapotranspiration and the water balance. Laboratory of Climatology, Drexel Institute of Technology, Centerton, NJ.

Wikipedia. (2014). West African Economic and Monetary Union. Retrieved May 12, 2014, from http://en.wikipedia.org/wiki/West_African_Economic_and_Monetary_Union

\section{Copyrights}

Copyright for this article is retained by the author(s), with first publication rights granted to the journal.

This is an open-access article distributed under the terms and conditions of the Creative Commons Attribution license (http://creativecommons.org/licenses/by/4.0/). 